\title{
Introduction of verticulture technique for utilization of spring land in Madrasah Tsanawiyah (MTS) ibnu sina City of Pematangsiantar
}

\author{
Yuan Alfinsyah Sihombing ${ }^{1 *}$, Susilawati ${ }^{1}$, Muhammad Zulham Efendi Sinaga ${ }^{2}$ \\ ${ }^{1}$ Departement of Physics, Faculty of Math and Science, University Sumatra Utara \\ ${ }^{2}$ Departement of Chemistry, Faculty of Math and Science, University Sumatra Utara \\ *Email: yuanalfinsyah@yahoo.com
}

\begin{abstract}
The area of agricultural land tends to decrease each year due to land conversion. In 2009 the area of land was reduced by 97 hectares. This is because the land is allocated to non-agricultural land. In urban areas, with all the busyness faced by people in urban areas they do not have time to farm. Moreover, not enough land is available or has no room to come into contact with agricultural cultivation. Not to mention that we often see dwellings that are quite dense and save land, how to foster hobbies and agricultural businesses, especially for housewives, teenagers or retirees. Currently various methods are carried out in line with technological developments. Verticulture is a technique of farming in a room / narrow land by utilizing a vertical plane as a place for farming which is carried out in stages. The purpose of verticulture is to make optimal use of narrow land. The stages of this implementation are the Socialization of Verticulture Cultivation Techniques at Ibnu Sina MTs, Assistance and the process of planting verticultural cultivation techniques, Evaluation and gift giving as awards to students and schools. The results achieved in this community service are products or goods produced in the form of verticulture, this socialization service is carried out in practice so that participants, students and teachers, can understand the techniques of plant cultivation with verticultural techniques as well as good planting and maintenance methods, Plant cultivation techniques with vertikultus techniques and ways of planting and good care have been understood by students in Madrasah Tsanawiyah (MTs) Ibnu Sina, Pematangsiantar City and have been well implemented.
\end{abstract}

Keyword: Land, verticulture, cultivation

\begin{abstract}
Abstrak
Luas lahan pertanian cendrung berkurang setiap tahunnya akibat adanya alih fungsi lahan. Pada tahun 2009 luas lahan berkurang $97 \mathrm{Ha}$. Hal ini dikarenakan lahan dialokasikan ke lahan non pertanian. Di daerah perkotaan, dengan segala kesibukan yang dihadapi masyarakat di perkotaan membuat mereka tidak sempat untuk bertani. Apalagi tidak tersedia cukup lahan alias tidak punya ruang untuk bersentuhan dengan budidaya pertanian. Belum lagi sering kita lihat pada pemukiman yang cukup padat dan hemat lahan, bagaimana menumbuhkan hobi dan usaha pertanian, khususnya bagi ibu rumah tangga, kaum remaja atau para pensiunan? Saat ini berbagai cara dilakukan seiring dengan perkembangan teknologi. Vertikultur merupakan teknik bercocok tanam diruang/lahan sempit dengan memanfaatkan bidang vertikal sebagai tempat bercocok tanam yang dilakukan secara bertingkat. Tujuan vertikultur adalah untuk memanfaatkan lahan yang sempit secara optimal. Adapun Tahapan pelaksanaan ini yaitu Sosialisasi Teknik Budidaya Vertikultur di MTs Ibnu Sina, Pendampingan dan proses penanaman teknik budidaya vertikultur, Evaluasi dan pemberian hadiah sebagai penghargaan kepada siswa dan sekolah. Adapun hasil yang telah dicapai pada pengabdian kepada masyarakat ini adalah Produk ataupun barang yang dihasilkan berupa vertikultur, jasa Sosialisasi ini dilakukan secara praktek langsung agar peserta yaitu siswa dan guru dapat memahami teknik budidaya tanaman dengan teknik vertikultus serta caracara penanaman dan perawatan yang baik, Teknik budidaya tanaman dengan teknik vertikultus serta cara-cara penanaman dan perawatan yang baik telah dipahami oleh siswa di Madrasah Tsanawiyah (MTs) Ibnu Sina Kota Pematangsiantar dan telah dilaksanakan dengan baik.
\end{abstract}

Kata Kunci: Lahan, vertikultur, budidaya 


\section{PENDAhUluan}

\subsection{Latar Belakang}

Permasalahn di bidang pertanian merupakan hal yang tidak ada habis-habisnya. Sehingga hal ini menjadi faktor penghambat perkembangan pertanian di dunia khususnya di indonesa. Permaslahan yang terjadi di antaranya merupakan masalah degradasi lahan, lahan marginal dan kurangnya pengembangan penerapan teknologi dalam bidang pertanian. Luas lahan pertanian cendrung berkurang setiap tahunnya akibat adanya alih fungsi lahan. Pada tahun 2009 luas lahan berkurang $97 \mathrm{Ha}$. Hal ini dikarenakan lahan dialokasikan ke lahan non pertanian.

Di daerah perkotaan, dengan segala kesibukan yang dihadapi masyarakat di perkotaan membuat mereka tidak sempat untuk bertani. Apalagi tidak tersedia cukup lahan alias tidak punya ruang untuk bersentuhan dengan budidaya pertanian. Belum lagi sering kita lihat pada pemukiman yang cukup padat dan hemat lahan, bagaimana menumbuhkan hobi dan usaha pertanian, khususnya bagi ibu rumah tangga, kaum remaja atau para pensiunan? Saat ini berbagai cara dilakukan seiring dengan perkembangan teknologi. Hal ini dilakukan agar tercipta suatu inovasi baru pengembangan pertanian dengan berbagai penerapan sistem teknologi.

Vertikultur berasal dari bahasa inggris, yaitu vertical dan culture. Vertikultur merupakan teknik bercocok tanam diruang/lahan sempit dengan memanfaatkan bidang vertikal sebagai tempat bercocok tanam yang dilakukan secara bertingkat. Tujuan vertikultur adalah untuk memanfaatkan lahan yang sempit secara optimal. Sistem bertanam secara vertikultur sekilas memang terlihat rumit, tetapi sebenarnya sangat mudah dilakukan. Tingkat kesulitan bertanam secara vertikultur tergantung kepada model dan sistem tambahan yang dipergunakan. Dalam model sederhana, struktur dasar yang digunakan mudah diikuti dan bahan pembuatannya mudah ditemukan, sehingga dapat diterapkan di rumah-rumah.

Kelebihan sistem pertanian vertikultur: (1). Efisiensi dalam penggunaan lahan. (2) Penghematan pemakaian pupuk dan pestisida. (3) Dapat dipindahkan dengan mudah karena tanaman diletakkan dalam wadah tertentu. (4) Mudah dalam hal monitoring/pemeliharaan tanaman. Sistem budidaya tanaman yang dilakukan secara vertikal atau bertingkat dapat dilakukan di dalam ruangan maupun luar ruangan. Sistem budidaya tanaman secara vertical atau bertingkat ini merupakan konsep penghijauan yang cocok untuk daerah perkotaan dan lahan terbatas. Misalnya, lahan 1 meter mungkin hanya bisa untuk menanam 5 batang tanaman, dengan sistem vertikal bisa untuk 20 batang tanaman.

Penggunaan lahan tertentu menjadi penggunaan lahan lainnya. Karena luas lahan yang tidak berubah, maka penambahan guna lahan tertentu akan berakibat pada berkurangnya guna lahan yang lainnya. Pendapat lain menyebutkan alih guna, alih fungsi, atau konversi lahan secara umum menyangkut transformasi dalam pengalokasian sumber daya alam dari satu penggunaan ke penggunaan lain.

Berubahnya orientasi ekonomi kota ke arah industrial tersebut juga akan mengubah kebiasaan dan adat istiadat masyarakat. Tingginya harga bahan makanan pokok, kesehatan, pendidikan dan kebutuhan lainnya mengakibatkan nilai ekonomi menjadi semakin tinggi dan menjadi pertimbangan rasional masyarakat

\section{METODE PELAKSANAAN}

\subsection{Sosialisasi Teknik Budidaya Vertikultur di MTs Ibnu Sina}

Pada tahap ini mitra akan diberikan 1 kali sosialisasi di minggu pertama yaitu pemaparan informasi-informasi mengenai teknik budidaya vertikultur dalam pemanfaatan lahan sempit dan alat yang digunakan adalah proyektor untuk pemaparan materi dalam power point, spidol dan papan tulis untuk penjelasan lanjutan. Sosialisasi ini dilaksanakan di ruangan kelas Madrasah Tsanawiyah Ibnu Sina dengan peserta sosialisasi ini adalah Siswa/i beserta guru. 


\subsection{Pendampingan dan proses pembuatan Vertikultur.}

Pada tahapan ini telah disediakan pipa vertikulur yang telah diberi lubang, media tanam berupa top soil, kompos, bibit sayur yang telah disemaikan selama 1 minggu dan MSG yang biasa ditemukan pada Ajinamoto. Tahapan pembuatan vertikultur berikut:

a. Dipacakkan pipa vertikultur sedalam $20 \mathrm{~cm}$ di dalam tanah.

b. Dimasukkan media tanam pada pipa dan dipadatkan.

c. Ditanam bibit sayur 4-5 bibit/lubang.

d. Disiram tanaman-tanaman yang sudah ditempatkan pada setiap lubang pipa vertikultur dengan bahan MSG yang dilarutkan dalam air untuk kesuburan tanah dan peningkatan pertumbuhan tanaman.

\subsection{Evaluasi dan pemberian hadiah sebagai penghargaan kepada siswa dan sekolah.}

Setelah 2 minggu, tahap selanjutnya adalah evaluasi pada tanaman vertikultur yang sudah dibuat oleh siswa/i sebelumnya. Tanaman sayur dilakukan pengecekan apakah setiap kelompok dari siswa/i MTs Ibnu Sina melakukan perawatan yang baik dan benar sesuai dengan intruksi dan sosialisasi sebelumnya. Siswa/i yang melakukan perawatan yang baik dan benar diberikan hadiah.

\section{HASIL DAN PEMBAHASAN}

Pada pengabdian kepada masyarakat dengan judul pengenalan teknik budidaya vertikultur untuk pemanfaatan lahan sempit di Madrasah Tsanawiyah (MTs) Ibnu Sina Kota Pematangsiantar telah dilaksanakan dengan baik. Adapun hasil yang telah dicapai pada pengabdian kepada masyarakat ini adalah:

a. Produk/Barang

Produk ataupun barang yang dihasilkan berupa vertikultur. Vertikultur ini terbuat dari pipa yang ditanam secara vertikal dengan melubangi pada sisi sampingnya. Lubang ini dimaksudkan sebagai tempat ditumbuhkannya tanaman sayuran. Pipa vertikultur ini sebelumnya diisi dengan tanah sebagai media tanam dan ditanam secara vertikal di atas tanah. Vertikultur ini dilakukan sebagai tempat penanaman sayuran untuk lahan yang sempit.

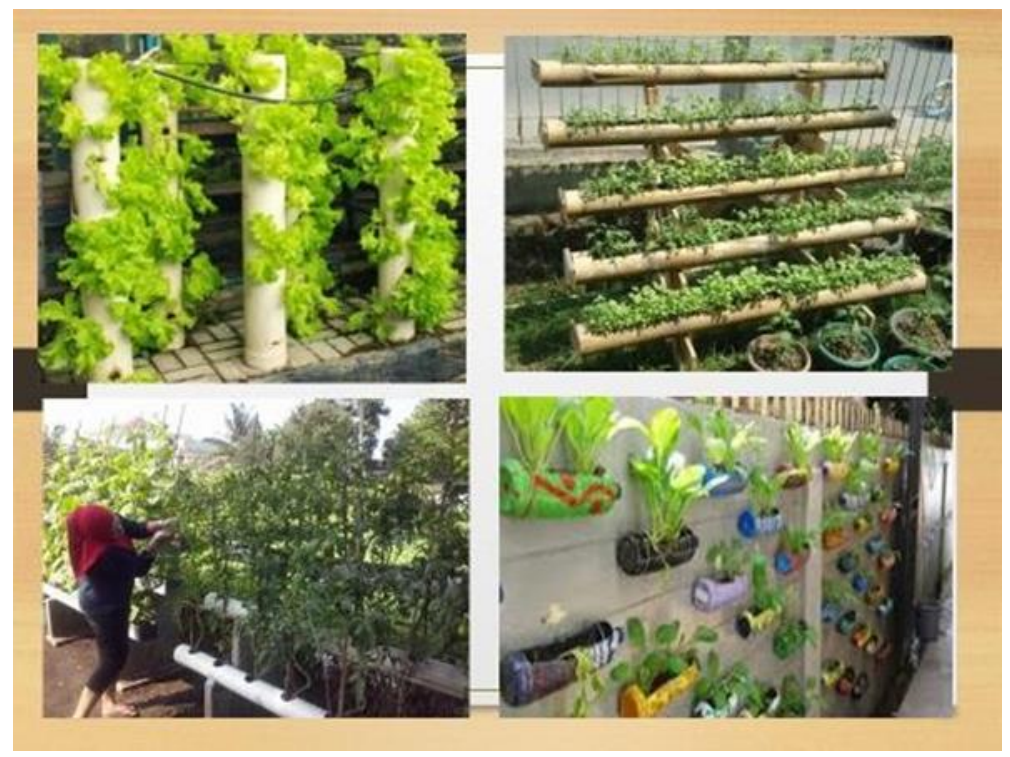

Gambar 1. Tanaman sayuraan pada budidaya vertikultur. 
b. Jasa

Pada pengabidan kepada masyarakat yang dilakukan di MTs Ibnu Sina Kota Pematangsiantar ini dilakukan sosialisasi secara klasikal berupa pemaparan materi vertikultur di dalam ruangan serta praktek langsung di lapangan. Sosialisasi ini dilakukan secara praktek langsung agar peserta yaitu siswa dan guru dapat memahami teknik budidaya tanaman dengan teknik vertikultus serta cara-cara penanaman dan perawatan yang baik. Dalam proses ini siswa dibagi dalam beberapa kelompok dan mempraktekkan sendiri. kerja siswa ini dimonitoring setelah 2 minggu kemudian dan diberikan hadiah kepada kelompok siswa yang sudah melakukan perawatan vertikultur dengan baik dan benar.

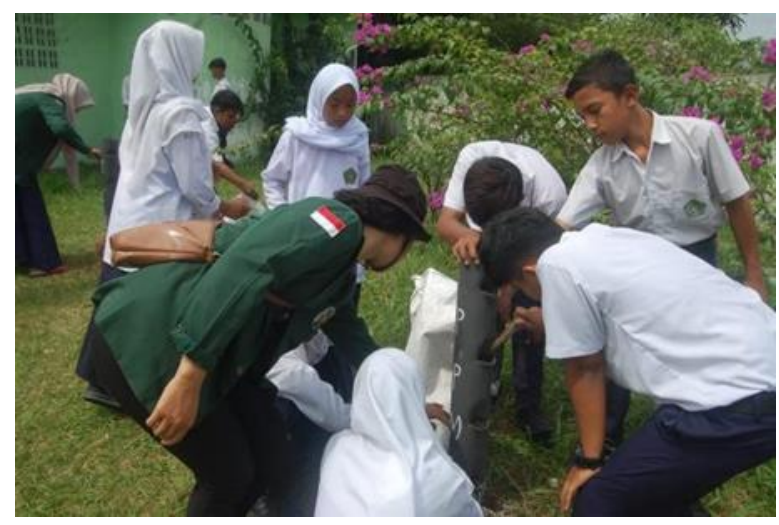

Gambar 2. Kegiatan penanaman bibit ke media.

c. Artikel Ilmiah

Artikel ilmiah masih dalam bentuk draft dan akan dimasukkan ke jurnal ilmiah pengabdian kepada masyarakat.

d. Video

Hasil kegiatan pengabdian kepada masyarakat ini akan dipublikasikan melalui media online yaitu youtube.

\section{KESIMPULAN}

Teknik budidaya tanaman dengan teknik vertikultus serta cara-cara penanaman dan perawatan yang baik telah dipahami oleh siswa di Madrasah Tsanawiyah (MTs) Ibnu Sina Kota Pematangsiantar dan telah dilaksanakan dengan baik.

\section{UCAPAN TERIMAKASIH}

Ucapan Terima Kasih kepada Lembaga Pengabdian kepada Masyarakat Universitas Sumatera Utara yang telah Menfasilitasi Pelaksanaan Pengabdian Masyarakat dan2. Ucapan terima kasih kepada pihak sekolah Madrasah Tsanawiyah (MTs) Ibnu Sina Kota Pematangsiantar yang sudah menerima tim pengabdian dengan baik. Ucapan terima kasih kepada seluruh tim yang sudah turut membantu mensukseskan kegiatan ini. 
Yuan Alfinsyah Sihombing, et.al. Introduction of verticulture technique

\section{DAFTAR PUSTAKA}

Anwar, E. A. Kosman, Husein Suganda. 2006. Pupuk Organik dan Pupuk Hayati. Jawa Barat: Balai Besar Litbang Sumber Daya Lahan Pertanian.

Azzahrawani, E. 2010. Kualitas Pupuk Cair dari Limbah Monosodium Glutamat (MSG) dengan Penambahan Sumber Hara Organik Tepung Tulang dan Guano yang Difermentasi dan Tanpa Fermentasi dengan Isi Rumen Sapi. Skripsi. Bogor: Departemen Ilmu Produksi dan Teknologi Peternakan Fakultas Peternakan IPB.

Desiliayarni, T., Y. Astuti, F. Fauzi, J. Endah H. 2003. Vertikultur Teknik Bertanam di Lahan Sempit. Jakarta: PT Agro Media Pustaka.

Hauser, P.M. 1985. Penduduk dan Masa Depan Perkotaan: Studi Kasus di Beberapa Daerah Perkotaan. Alih bahasa: Masri Marif. Jakarta: Yayasan Obor. 